\title{
Effect of Red Mud Content on Strength and Efflorescence in Pavement using Alkali-Activated Slag Cement
}

\author{
Kim Hyeok-Jung ${ }^{1)}$, Suk-Pyo Kang ${ }^{2), *}$, and Gyeong-Cheol Choe ${ }^{3)}$
}

(Received September 28, 2017, Accepted February 6, 2018)

\begin{abstract}
Efflorescence which severely occurs in alkali-activated slag cement can cause reduction of strength and durability due to calcium leaching. In the work, efflorescence characteristics in pavement containing red mud which can be affected by strong alkaline were investigated through various tests such as compressive strength, porosity, absorption, efflorescence area, alkali leaching content, and properties of the efflorescence compound. The compressive strength of pavement was evaluated to be higher over $15.0 \mathrm{MPa}$ in all cases regardless of replacement ratio of red-mud and binder type, which can provide a reasonable strength for walking and bike lanes. The pavement with red mud was applicable to parking lots only when the replacement ratio of red-mud is within $10 \%$. The efflorescence area increased with a higher replacement ratio of red mud and its propagation appeared though the efflorescence was removed through evaporation of moisture. However, the area of efflorescence gradually decreased with the repetition of the test.
\end{abstract}

Keywords: pavement, alkali-activated slag cement, red mud, efflorescence, compaction.

\section{Introduction}

With increasing significance of human-friendly environment and sustainability, eco-friendly pavement materials have been used for bike trails, local roads, and parking lots, which can give emotional stability. Natural loess and soils are conventionally used for soil-pavement as a binder-cement or a stabilizing agent (Adebisi et al. 2013; Dipti et al. 2015; Kang 2016). However, the soil texture may cause imperfect integration due to cement hydration, which negatively affects both durability and aesthetic condition, producing surface cracks and dust scattering, propagates to economic losses. As an alternative to the expensive soil pavement, various studies have been performed on the red mud which is produced as a byproduct in the alumina production process from the bauxite ore. $\mathrm{Fe}_{2} \mathrm{O}_{3}$ accounts for about $22 \%$ in the chemical formation of red mud, playing an important role in forming the reddish-yellow color that can give the feeling of natural loess. For the reason, red mud is reported to be capable of replacing conventional soil pavement with sufficient quality (Liu et al. 2011; David et al.

\footnotetext{
${ }^{1)}$ Elastomer TS\&D Team, Kumho Petrochemical R\&BD Center, Daejeon 34044, South Korea.

${ }^{2)}$ Department of Architecture, Woosuk University, Jincheon 27841, South Korea.

${ }^{3)}$ College of Engineering 2-104, Chungnam National University, 99 Daehak-ro, Yuseong-gu, Daejeon 34134, Republic of Korea.

*Corresponding Author; E-mail: ksp0404@empal.com Copyright $\odot$ The Author(s) 2018. This article is an open access publication
}

2017; Kang 2016). Another effort for utilizing red mud as an activator has been made for alkali slag red mud cement in the construction industry, which is so called clinker-free cement (Gonga and Yang 2000; Pan et al. 2002, 2003). On the other hand, several studies have been carried out for the use of a powdery industrial byproduct as a replacement for expensive liquid activator (Kang 2012).

Efflorescence has been considered be relatively insignificant since it does not cause a rapid structural problem in normal Reinforced Concrete (RC) structure or member, however, alkali-activated cement is very vulnerable to efflorescence so that extreme damages from efflorescence has been reported (Kresse 1987; Bensted 2000; Zhang et al. 2014). In particular, alkali-activated binders that contain sodium-based activators have been reported to be more vulnerable to efflorescence. This is due to a increase in $\mathrm{Na}_{2} \mathrm{O} / \mathrm{Al}_{2} \mathrm{O}_{3}$ ratio. When $\mathrm{Na}_{2} \mathrm{O}$ exists in an unreacted state increases, it can accelerate relatively easy movement of sodium ions in the alumino-silicate structure which is a product of the alkali-activated binder. Consequently, the alkali-activated binder is known to be more vulnerable to efflorescence in comparison to Ordinary Portland Cement (OPC) (Dow and Glasser 2003; Kresse 1987; Kani et al. 2012).

In the work, alkali-activated slag red-mud pavement is developed for feasible application to construction industry using red mud-based binder. The efflorescence characteristics which can be caused by strong alkaline in red-mud are investigated considering evaluation of pavement compaction, compressive strength, porosity, absorption, efflorescence area, alkali leaching content, and properties of the efflorescence compound. In addition, the results are compared with those from OPC-based pavement. 


\section{Materials and Experimental Program}

\subsection{Materials}

\subsubsection{Binder Properties}

The physical and chemical properties of OPC and AAS (Alkali-Activated Slag Cement) are shown in Table 1.

AAS based on Ground Granulated Blast Furnace Slag (GGBFS) is clinker free since it is made from industrial byproducts, including desulfurized gypsum and high-calcium fly-ash. The chemical formation of the AAS cement is $\mathrm{SiO}_{2} 21.2 \%, \mathrm{Al}_{2} \mathrm{O}_{3} 8.8 \%, \mathrm{CaO} 46.6 \%$, and $\mathrm{SO}_{3} 11.5 \%$. Compared with $\mathrm{OPC}$, it has less $\mathrm{CaO}$, and more $\mathrm{SO}_{3}$ and $\mathrm{Al}_{2} \mathrm{O}_{3}$. In addition, it has a specific surface area of $4058 \mathrm{~cm}^{2} / \mathrm{g}$ with $2.83 \mathrm{~g} / \mathrm{cm}^{3}$ of density. It implies that it is lighter and finer than OPC. Figure 1 shows the results of XRD analysis of hydration reaction of pastes by ages. As an alkaline activator for GGBFS, only industrial byproducts such as desulfurized gypsum and high-calcium fly ash are used, so the hydration products consist of ettringite, portlandite, and unreacted gypsum (Moon et al. 2009).

\subsubsection{Red Mud Properties}

Approximately two tons of red mud are produced in sludge with $40.0-60.0 \%$ moisture content for one ton of $\mathrm{Al}_{2} \mathrm{O}_{3}$ production through Bayer process. An annual production amount in Korea is approximately thirty tons. The sludge with $40.0-60.0 \%$ moisture content is dried to about $10.0 \%$, then ground into granulated type. The physical and chemical properties of the dried red mud are listed in Table 2. In the chemical composition, the summation of $\mathrm{SiO}_{2}, \mathrm{Al}_{2} \mathrm{O}_{3}$, and $\mathrm{Fe}_{2} \mathrm{O}_{3}$ reaches about $80 \%$ of the total weight. $\mathrm{Fe}_{2} \mathrm{O}_{3}$ accounting for red mud color (red brown) is evaluated to be $22.8 \%$ of the weight. The weight ratio of $\mathrm{Na}_{2} \mathrm{O}$ which produces strong alkali and mainly causes efflorescence is observed to be $10.0 \%$. The density and moisture content show $3.5 \mathrm{~g} / \mathrm{cm}^{3}$ and $10.2 \%$, respectively.

Since sodium hydroxide is used in the extracting process of aluminum from Bauxite ores, sodium hydroxide solution still remains, which causes strong alkali over $11.0 \mathrm{of} \mathrm{pH}$. The strong alkaline property in red-mud means that it can utilized as an activator for GGBFS. The specific surface area of the dried red mud is $23.53 \mathrm{~m}^{2} / \mathrm{g}$ and the average grain diameter is $2.75 \mu \mathrm{m}$. The average grain diameter of red mud is even smaller than that of micro-cement $(4-6 \mu \mathrm{m})$. The small particles can provide a packing effect on binder matrix and strength development so that strength reduction due to efflorescence can be compensated (Al-Akhras and Smadi 2004). Figure 2 shows the particle size distribution of the red

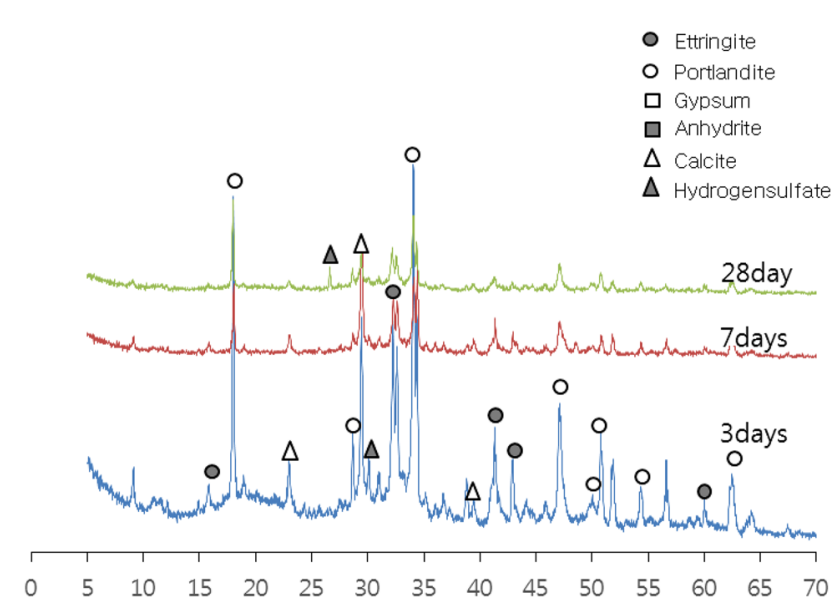

Fig. 1 XRD pattern of AAS paste.

mud, indicating that the particle size is only $10.0 \%$ level compared with the average grain diameter for OPC and AAS.

\subsubsection{Aggregate Properties}

The physical properties of the crushed fine aggregate are shown in Table 3 and Fig. 3 shows the comparison of the size distribution with the standard size distribution specified in Unified Standard Specifications for Concrete Construction. The size distribution of fine aggregate used in this study satisfies the standard.

\subsection{Experimental Program \\ 2.2.1 Mix Design}

The mix proportions for red mud pavement are listed in Table 4. In order to evaluate the efflorescence in AAS redmud pavement with replacement ratio of red-mud, red-mud was replaced with total mass of cement by $0,10,20$, and $30 \%$. Dry pavement was manufactured by mixing $10 \%$ of binder and $90 \%$ of crushed sand of the total mass of pavement except for mass of water. The mass of water was determined by using the optimum water content.

\subsubsection{OMC Evalaution Test}

The pavement properties differ with the effect of compaction, dry density, and optimum water content. With higher water content in the binder, the moisture in the particles serves as a lubricant, which increases compaction effect and dry density. In the test, the moisture content at the highest dry density is set as the optimum water content. For calculating Optimum Moisture Content (OMC), compaction was repeated referred to KS F 2312 and the period to

Table 1 Physical properties and chemical composition of binder.

\begin{tabular}{c|c|c|c|c|c|c|c|c|c}
\hline \multirow{2}{*}{$\begin{array}{c}\text { Type of } \\
\text { binder }\end{array}$} & $\begin{array}{c}\text { Specific } \\
\text { surface } \\
\text { area }\left(\mathrm{cm}^{2} / \mathrm{g}\right)\end{array}$ & $\begin{array}{c}\text { Density } \\
\left(\mathrm{g} / \mathrm{cm}^{3}\right)\end{array}$ & & Ig. loss & \multicolumn{6}{|c}{ Chemical composition (\%) } \\
\cline { 5 - 10 } & & & $\mathrm{SiO}_{2}$ & $\mathrm{Al}_{2} \mathrm{O}_{3}$ & $\mathrm{Fe}_{2} \mathrm{O}_{3}$ & $\mathrm{CaO}$ & $\mathrm{MgO}$ & $\mathrm{SO}_{3}$ \\
\hline \hline OPC & 3144 & 3.15 & 1.32 & 21.7 & 5.7 & 3.2 & 63.1 & 2.8 & 2.2 \\
\hline AAS & 4058 & 2.83 & 2.23 & 22.1 & 8.9 & 1.4 & 54.9 & 3.3 & 5.2 \\
\hline
\end{tabular}

$O P C$ Ordinary Portland Cement, $A A S$ alkali-activated slag cement. 
Table 2 Physical properties and chemical composition of red mud.

\begin{tabular}{|c|c|c|c|c|c|c|c|c|c|c|c|}
\hline \multirow[t]{2}{*}{ Type } & \multirow{2}{*}{$\begin{array}{c}\text { Specific } \\
\text { surface } \\
\text { area }\left(\mathrm{m}^{2} / \mathrm{g}\right)\end{array}$} & \multirow{2}{*}{$\begin{array}{c}\text { Average } \\
\text { particle } \\
\text { diameter } \\
(\mu \mathrm{m})\end{array}$} & \multirow{2}{*}{$\begin{array}{l}\text { Density } \\
\left(\mathrm{g} / \mathrm{cm}^{3}\right)\end{array}$} & \multirow{2}{*}{$\begin{array}{l}\text { Moisture } \\
\text { content } \\
\text { ratio }(\%)\end{array}$} & \multicolumn{7}{|c|}{ Chemical composition (\%) } \\
\hline & & & & & $\mathrm{SiO}_{2}$ & $\mathrm{Al}_{2} \mathrm{O}_{3}$ & $\mathrm{Fe}_{2} \mathrm{O}_{3}$ & $\mathrm{CaO}$ & $\mathrm{MgO}$ & $\mathrm{SO}_{3}$ & $\mathrm{Na}_{2} \mathrm{O}$ \\
\hline Dry & 23.53 & 2.75 & 3.50 & 10.2 & 38.8 & 16.1 & 22.8 & 3.4 & 0.2 & 0.0 & 10.0 \\
\hline
\end{tabular}

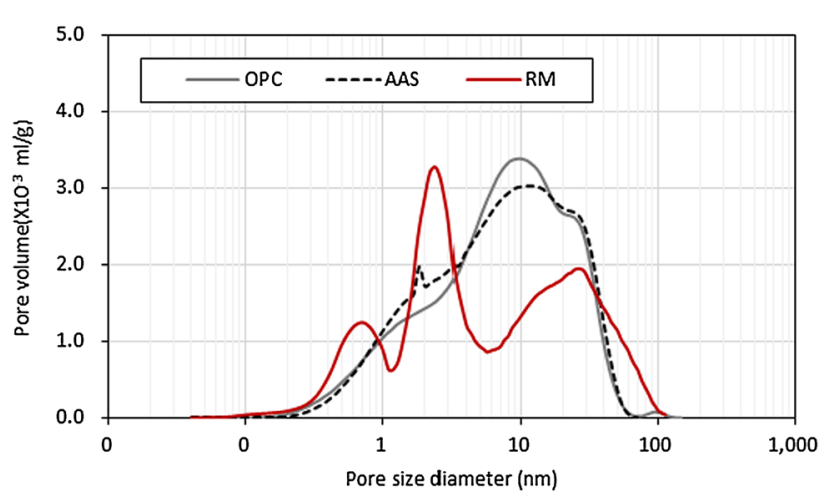

Fig. 2 Particle size distribution.

hardening after the mixing was measured. The draft angle, height, and volume of the mold are $10.0 \mathrm{~cm}, 12.7 \mathrm{~cm}$, $1000 \mathrm{~cm}^{3}$, respectively. The diameter, drop height and weight of the rammer are $5 \mathrm{~cm}, 30 \mathrm{~cm}$, and $2.5 \mathrm{kgf}$, respectively. Compaction was conducted 25 times per each layer for three layers. OMC $\left(\omega_{001}\right)$ is evaluated referred to KS F 2312 A taking into account the period from mixing to hardening of the pavement. The water content of the pavement in compaction was calculated following which the OPC and the highest dry density were determined in accordance with the compaction curve after wet and dry density were calculated using Eq. (1)

$$
Y_{t}=\frac{M_{2}-M_{1}}{V}
$$

where $Y_{t}$ is wet density $\left(\mathrm{g} / \mathrm{cm}^{3}\right), M_{2}$ is the total mass $(\mathrm{g}), \mathrm{M}_{1}$ is the mass of the plate, and $\mathrm{V}$ is the volume of the mold $\left(\mathrm{cm}^{3}\right)$ Dry density is obtained from Eq. (2).

$$
Y_{d}=\frac{Y_{t}}{1+\frac{\omega}{100}}
$$

where $Y_{d}$ is dry density $\left(\mathrm{g} / \mathrm{cm}^{3}\right), Y_{t}$ is wet density $\left(\mathrm{g} / \mathrm{cm}^{3}\right)$, and $\omega$ is water content.

\subsubsection{Compressive Strength Test}

For compressive strength evaluation, the dry soil pavement was mixed with OMC based on the Standards in Korea (SPSKCICO-001:2003) using a pan-type mixer for three minutes and compacted in $\Phi 10 \times 20 \mathrm{~cm}$ molds. The

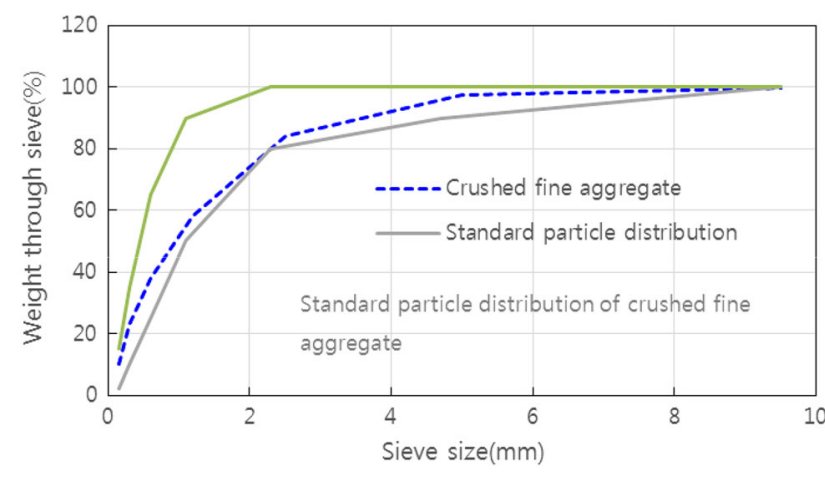

Fig. 3 Particle size distribution of fine aggregate.

rammer whose diameter, falling height and weight are $5 \mathrm{~cm}$, $30 \mathrm{~cm}$, and $2.5 \mathrm{kgf}$ was used, respectively. Compaction was performed 25 times per layer for three layers. Dry soil pavement samples were prepared and cured for 28 days in the room condition with $25 \mathrm{C}$ and $60 \%$ of R.H. After curing for 14 days and 28 days, compressive strength was evaluated referred to KS F 2405. Figure 4 shows the compaction of the pavement for compressive strength test and the rammer used.

\subsubsection{Efflorescence Acceleration Test}

The specimens for efflorescence test were produced with a size of $\Phi 100 \times 50 \mathrm{~mm}$ which is identical to the one used for compressive strength test. After 28 days of curing, the side surface of the sample is sealed with epoxy and about $6.0 \mathrm{~mm}$ of the bottom is immersed in distilled water for 14 days in the condition of $7 \mathrm{C}$ of temperature and $50 \%$ of R.H. The photos for efflorescence area are taken after 14 days of accelerating period and the area is quantitatively evaluated through Paint.NET software. The efflorescence grading is evaluated based on the recommendation of As/NZS 6656.6 in Australia.

\subsubsection{Alkali Leaching Test}

The pavement samples are crushed after the accelerated efflorescence test and the powder is mixed with distilled water in a weight ratio of 1:50. They are exposed to the same conditions of the accelerated efflorescence test for $48 \mathrm{~h}$. After $48 \mathrm{~h}, 20 \mathrm{~mL}$ of the mixed water is obtained through filtering. Since soluble $\mathrm{Na}^{+}$and $\mathrm{Ca}^{2+}$ are the major ions for

Table 3 Properties of fine aggregate.

\begin{tabular}{c|c|c|c|c|c}
\hline Type & Density $\left(\mathrm{g} / \mathrm{cm}^{3}\right)$ & Absorption (\%) & $\begin{array}{c}0.08 \mathrm{~mm} \text { sieve passing } \\
(\%)\end{array}$ & Fineness modulus & $\begin{array}{c}\text { Solid volume } \\
\text { percentage }(\%)\end{array}$ \\
\hline \hline Crushed fine aggregate & 2.59 & 1.38 & 1.18 & 2.87 & 64.1 \\
\hline
\end{tabular}


Table 4 Mix design of pavement.

\begin{tabular}{|c|c|c|c|c|c|}
\hline \multirow[t]{2}{*}{ Type of binder } & \multicolumn{3}{|c|}{ Unit weight (kg/ton) } & \multirow[t]{2}{*}{ Water content $(\%)$} & \multirow[t]{2}{*}{ W/B (\%) } \\
\hline & Cement & Red mud & Sand & & \\
\hline \multicolumn{6}{|c|}{ " Ordinary Portland Cement (OPC) } \\
\hline OPC0 & 100 & 0 & \multirow[t]{4}{*}{900} & \multirow[t]{4}{*}{ Optimum water content } & \multirow{4}{*}{$\begin{array}{c}\text { Changed by optimum } \\
\text { water content }\end{array}$} \\
\hline OPC10 & 90 & 10 & & & \\
\hline OPC20 & 80 & 20 & & & \\
\hline OPC30 & 70 & 30 & & & \\
\hline \multicolumn{6}{|c|}{ Alkali-activated slag cement (AAS) } \\
\hline AAS0 & 100 & 0 & & & \\
\hline AAS10 & 90 & 10 & & & \\
\hline AAS20 & 80 & 20 & & & \\
\hline AAS30 & 70 & 30 & & & \\
\hline
\end{tabular}

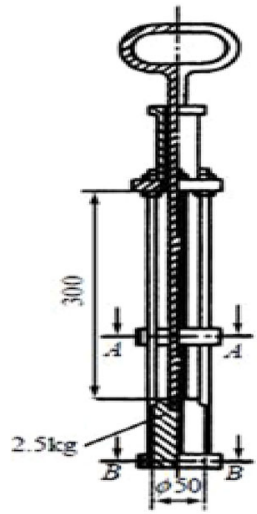

(a) Rammer

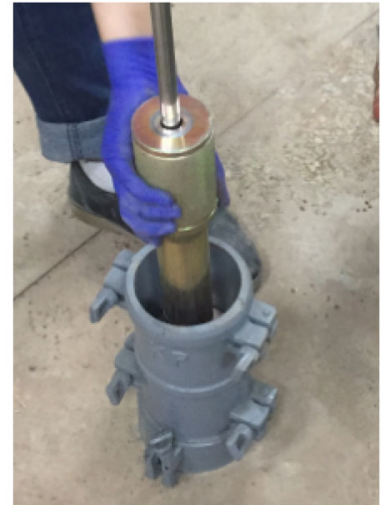

(b) Compaction

Fig. 4 Compaction rammer.

efflorescence, the concentrations of them are measured through ICP (Inductively Coupled Plasma) analysis. The results are compared with the results before accelerated efflorescence.

\section{Result and Discussions}

\subsection{Compactability Evaluation}

Figure 5 shows the compaction curve of the pavement in terms of replacement ratio of red mud by binder type. In the compaction curve, the dry density changes gradually depending on the water content, which implies that there is no distinct difference in compaction according to the replacement ratio of red mud. In all binders, OMC increases and dry density decreases in the compaction curve. The OMC is calculated and plotted in Fig. 6 considering the replacement ratio of red mud and binder type.

The OMC appears to increase as the replacement ratio of red mud is getting higher. The OMC is relatively higher in ASS pavement compared with that in OPC. The results with binder type are shown to be $9.1-10.2 \%$ in AAS and

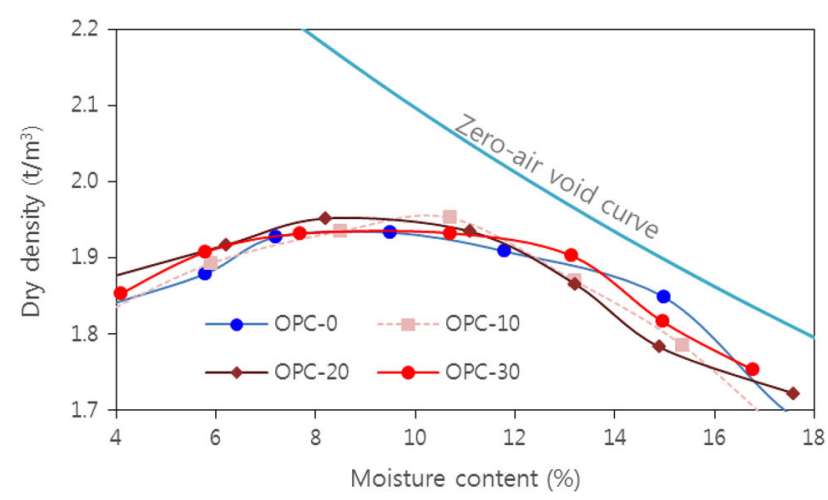

(a) OPC

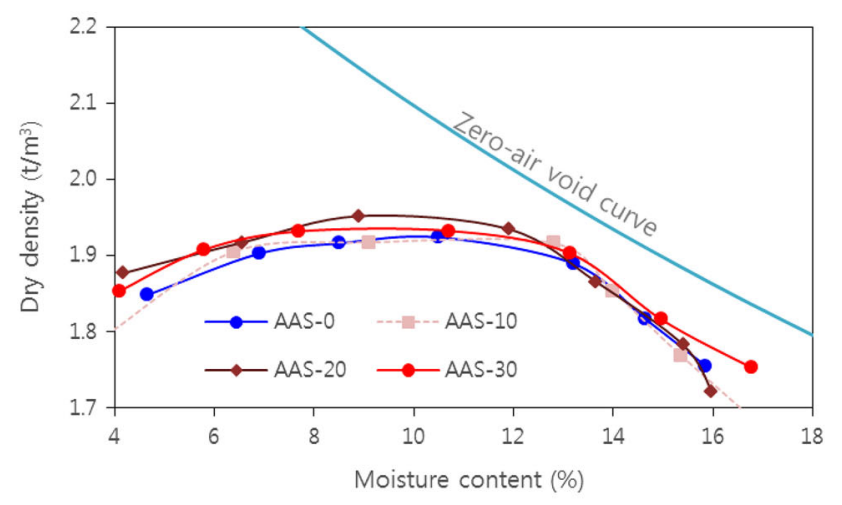

(b) AAS

Fig. 5 Compaction characteristics with red mud replacement ratio.

$8.4-9.9 \%$ in OPC, respectively. In other words, the OMC in ASS is $0.3-0.8 \%$ higher than that in OPC. As shown in Fig. 2, the size distribution of AAS is relatively gradual, which implies that there are more microfines whose surfaces are wide enough to hold a large quantity of hygroscopic water. In addition, the OMC by mix proportion of red mud is observed to be $12 \%$ higher in AAS 30 than in AAS 0 , while it is $17 \%$ higher in OPC 30 than in OPC 0. Similarly, the reason for increasing $\mathrm{OMC}$ with higher red mud replacement ratio is that the red-mud is silt and clay with an average 


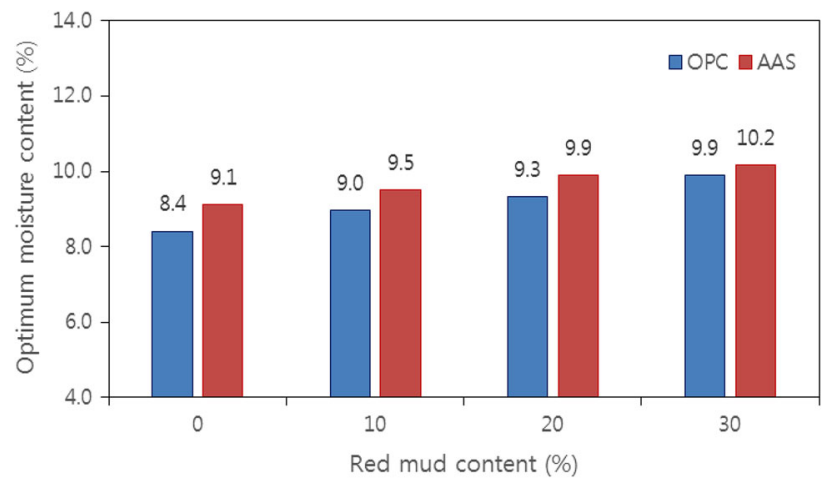

Fig. 6 Optimum moisture content with red mud replacement ratio.

particle size of $2.75 \mu \mathrm{m}$ with high micro-fine content. Red mud has relatively higher density and a larger specific surface area compared with the binders such as OPC and ASS, so that its physical properties are similar to those of silt and clay (Bahmani et al. 2014). Therefore with increasing replacement ratio of red mud, it moves to the right in the compaction curve, from which it can be interpreted that the $\mathrm{OMC}$ increases while the highest dry density decreases.

\subsection{Compressive Strength Evaluation}

Figure 7 shows the results of compressive strength with varying red mud replacement ratios. The compressive strength at 28 days is evaluated to be $18.9-27.0 \mathrm{MPa}$ in AAS, and 18.4-28.8 $\mathrm{MPa}$ in OPC, showing a similar level between the cases, which shows a slight different trend from the previous results (Kang and Kwon 2017) where the compressive strength of ASS mortar was observed to be lower than that of OPC mortar. It is inferred that industrial byproducts like high-calcium fly ash and desulfurized gypsum are easily expandable after compacting by the hydration reaction, which can induce swelling pressure to soil particles.

Regardless of binder type, the higher replacement ratio of red mud is in OPC or in AAS, the lower the compressive strength is measured. The degradation of the compressive strength caused by the mix proportion of red-mud appeared to be comparatively less in ASS than in OPC. In the related Standards in Korea (SPSKCICO-001:2003), the

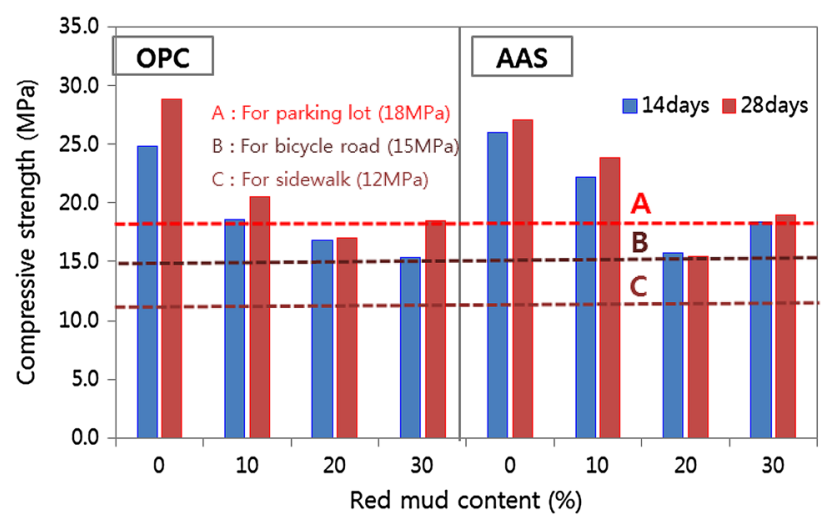

Fig. 7 Optimum moisture content with red mud replacement ratio. performance of compressive strength is classified into three stages. It is specified that a strength over $18 \mathrm{MPa}$ for parking lots, a strength higher over $15 \mathrm{MPa}$ for bike lanes, and a strength over $12 \mathrm{MPa}$ for walking lanes are required considering user's needs. In the results, the compressive strength was evaluated over $15 \mathrm{MPa}$ in all specimens regardless of the replacement ratios of red-mud and binder types. However, it is applicable to parking lots only when the replacement ratio of red mud is within the range of $10 \%$.

\subsection{Porosity Evaluation}

Figure 8 shows the cumulative porosity with replacement ratio of red mud by binder type. Total porosity appears to be higher in ASS than in OPC. The total porosity volume appeares to be great in OPC with replacement ratio of redmud, while there was no significant effect of red mud replacement on porosity in AAS. In the case if AAS 0 , the cumulative porosity appears to be $0.94 \mathrm{ml} / \mathrm{g}$, which is $34.2 \%$ higher compared to $0.70 \mathrm{ml} / \mathrm{g}$ of control case (OPC 0 ). However, as the replacement ratio of red mud becomes higher, there is no big change in the result in AAS, from 0.94 to $0.93 \mathrm{ml} / \mathrm{g}$, while it is increasing in $\mathrm{OPC}$, from 0.70 to $0.93 \mathrm{ml} / \mathrm{g}$. This, as shown in Fig. 9, seems to be due to the fact that AAS has more 10-1000 nm capillary pores compared with OPC. For this reason, even though red-mud is more mixed with AAS, the volume of capillary pores is almost unaffected in AAS, while the volume of capillary pores increases in OPC. The volume along $1000-100,000 \mathrm{~nm}$ pores decreases in AAS, but there is no significant difference found in OPC. Therefore, if red mud is mixed instead of a binder, the amount of cement needed for hydration reaction decreases in OPC, which leads to a reduction in porosity. Meanwhile, AAS is affected less by red mud content with almost constant porosity due to the filling effect of red-mud. The results of pore size distribution are shown in Fig. 9.

\subsection{Efflorescence Characterization}

As shown in Table 5, the degree of efflorescence is quantitatively categorized into 5 levels considering the efflorescence area. XRD analyses are performed in order to characterize the efflorescence compounds. The efflorescence

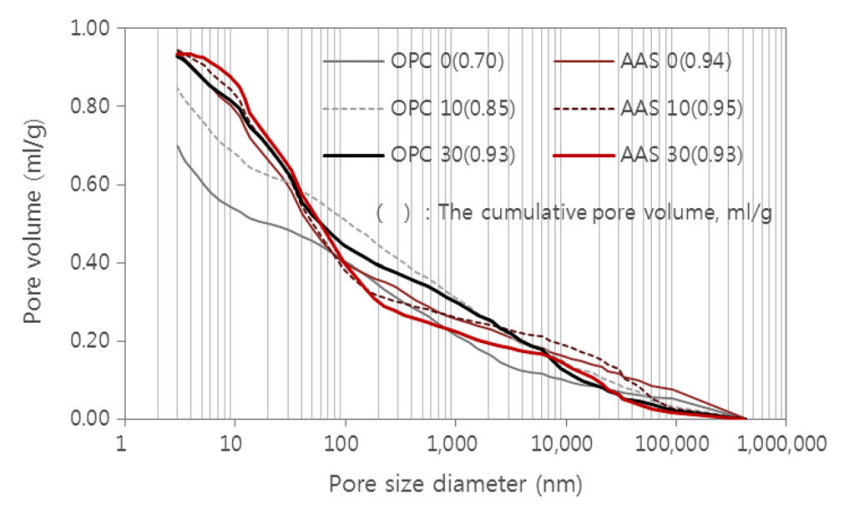

Fig. 8 Total pore volume with red mud replacement ratio. 


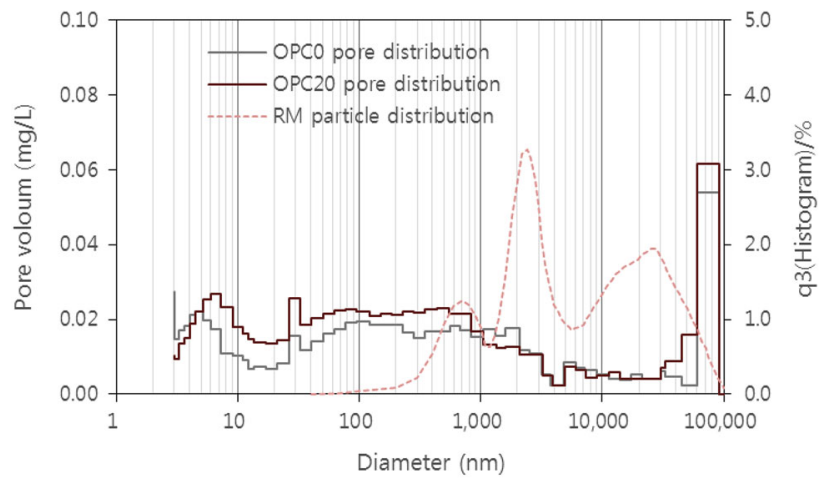

(a) OPC

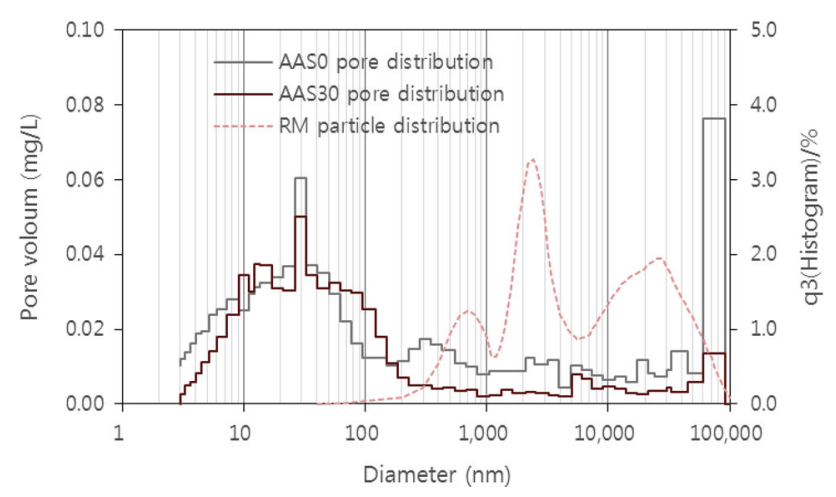

(b) AAS

Fig. 9 Pore size distribution with red mud replacement ratio.

area and class are listed in Table 6 from the test. The efflorescence area increases with a higher replacement ratio of red mud. The efflorescence area with repeating tests after removing the efflorescence is shown in Fig. 10.

As shown in in Fig. 10, the efflorescence continues to appear even after removal of efflorescence, however the area of efflorescence tends to gradually decrease with the repetition of the test. In the first test, the efflorescence area varies from 15 to $75 \%$ in the specimens with a replacement ratio of $20 \%$ of red mud. However, after the fourth test, the area appeared to be less than $10 \%$ overall. In the first test for $30 \%$ replacement ratio, the area is $75 \%$ but after the fourth test, it decreases to around 10-20\%. Through the results, it is found that the efflorescence cannot be completely removed, but the area can be dramatically reduced with few times of efflorescence removal. In order to examine the main mechanism of efflorescence, the concentrations of $\mathrm{Na}^{+}$and $\mathrm{Ca}^{2+}$ leached are measured and the results are shown in Fig. 11 where the concentrations of soluble $\mathrm{Na}^{+}$and $\mathrm{Ca}^{2+}$ leached after the fifth efflorescence test and the amount of $\mathrm{Na}^{+}$and $\mathrm{Ca}^{2+}$ before the first test are compared.

The concentrations of $\mathrm{Na}^{+}$leached from OPC 0 is $0.46 \mathrm{mg} / \mathrm{l}$, and from AAS 0 is $0.81 \mathrm{mg} / \mathrm{l}$. However, as more red-mud is replaced, the $\mathrm{Na}^{+}$content increases both in OPC 30 (to $24.26 \mathrm{mg} / \mathrm{l}$ ) and in AAS 30 to $(22.04 \mathrm{mg} / \mathrm{l})$. It was 52.7 times higher in OPC 30 compared with OPC 0 and 27.2 times higher in AAS 30 compared with AAS 0. This is because OPC and AAS had a small quantity of $\mathrm{Na}_{2} \mathrm{O}, 0.4$ and $0.2 \%$, respectively but red mud contains about $10.0 \%$ $\mathrm{Na}_{2} \mathrm{O}$. When red mud with sufficient $\mathrm{Na}_{2} \mathrm{O}$ is replaced with OPC, the supply of $\mathrm{Na}_{2} \mathrm{O}$ increases. Additionally in all specimens, the content of $\mathrm{Na}^{+}$leached decreases after the fifth efflorescence test compared with initial condition. In particular, the decrease appears to be greater with more red mud content. The leached $\mathrm{Na}^{+}$becomes the main ingredient of the efflorescence. As more efflorescence appears, considerable eluted $\mathrm{Na}^{+}$is also removed during the removal process.

The efflorescence in OPC-based concrete is generated by free $\mathrm{CaO}$ or $\mathrm{Ca}(\mathrm{OH})_{2}$, a product of hydration reaction (Kresse 1987; Bensted 2000), so that more efflorescence is generated when sufficient amount of $\mathrm{Ca}(\mathrm{OH})_{2}$ is produced through the hydration reaction. Therefore, it is expected that more $\mathrm{Ca}^{2+}$ ions are leached out from the pavement. Regarding the leached amount of $\mathrm{Ca}^{2+}$, OPC 0 is 1.9 times higher before the first efflorescence test while it is 1.7 times higher after the fifth test. In particular, the higher mix proportion of red-mud is, the less $\mathrm{Ca}^{2+}$ is eluted. This is because $\mathrm{CaO}$ content in OPC and AAS is 63.1 and $54.9 \%$, respectively, while $\mathrm{CaO}$ content in red mud is only $3.4 \%$. If red mud is replaced with OPC, the source of $\mathrm{CaO}$ decreases. In addition, after the fifth efflorescence test, it is found that the amount of $\mathrm{Ca}^{2+}$ leached is slightly decreases compared with that before the first test. But the $\mathrm{Ca}^{2+}$ appeares to decrease less compared with $\mathrm{Na}^{+}$. It imples that the content of $\mathrm{Ca}^{2+}$ removed along with the efflorescence compound is lower. Compared with the $\mathrm{Na}^{+}$, it has a relatively small effect on efflorescence.

To identify how the leaching content of $\mathrm{Na}^{+}$and $\mathrm{Ca}^{2+}$ affected efflorescence, XRD analysis of efflorescent compound on the pavement is performed. The results of XRD analysis are shown in Fig. 12.

Table 5 Quantification of efflorescence degree.

\begin{tabular}{c|c}
\hline Degree & Efflorescence area \\
\hline \hline I & None \\
\hline II & $<10 \%$ \\
\hline III & Above $10 \%$, less than $30 \%$ \\
\hline IV & Above $30 \%$, less than $50 \%$ \\
\hline V & Above $50 \%$ \\
\hline
\end{tabular}


Table 6 Efflorescence characteristics.

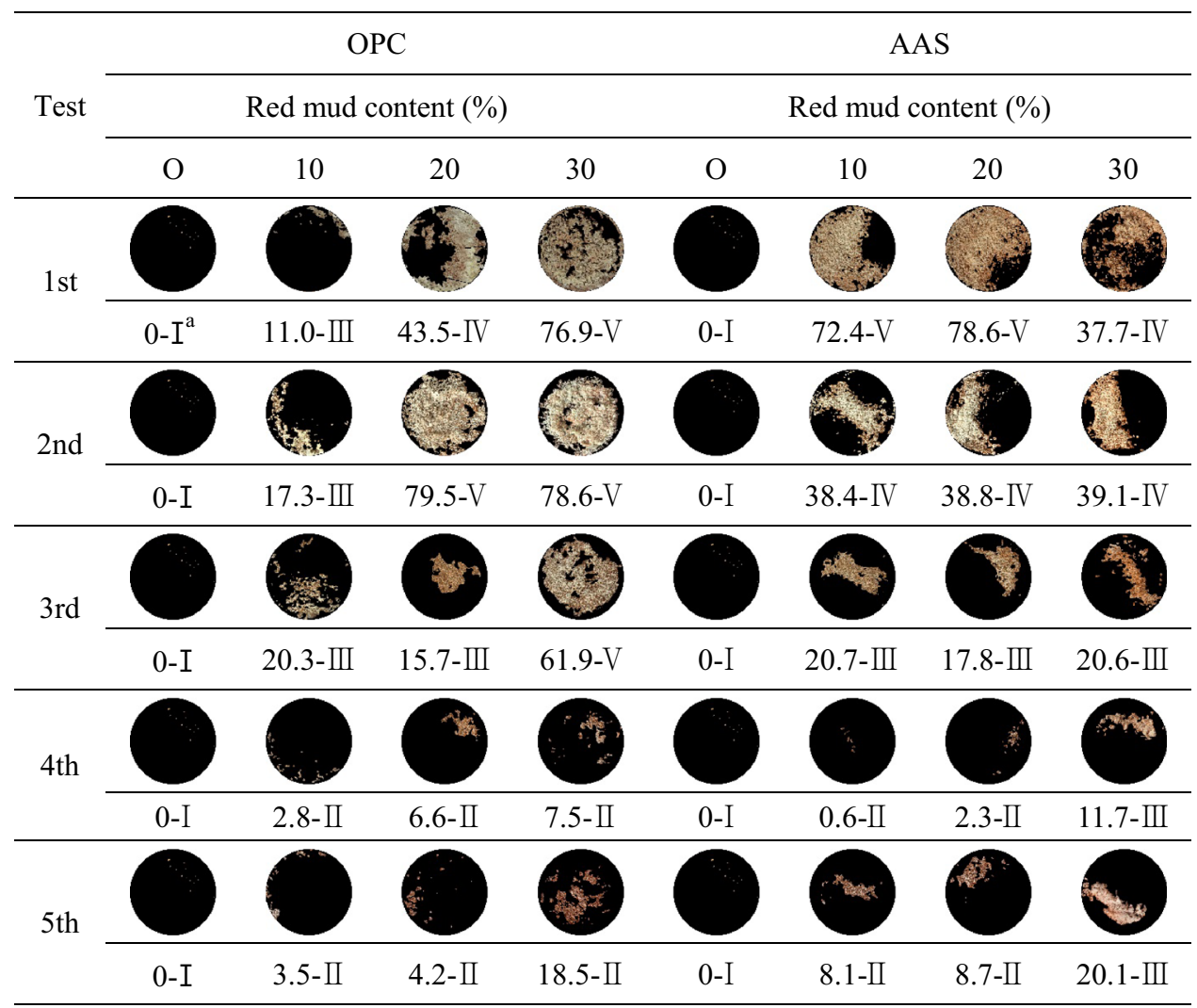

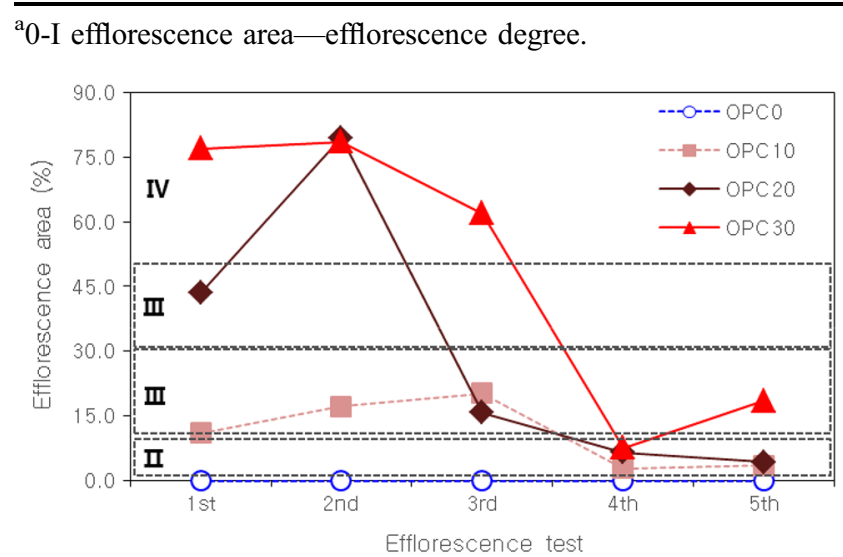

(a) OPC

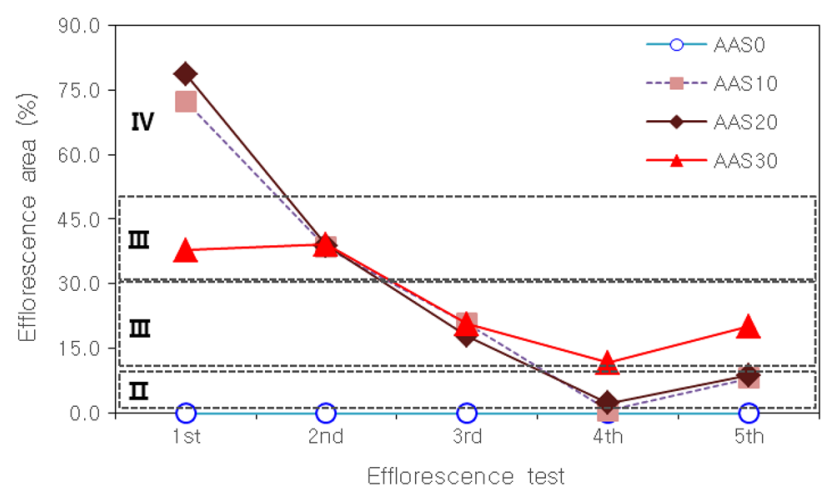

(b) AAS

Fig. 10 Efflorescence area with the number of retests.
In the efflorescence from OPC binder with red mud $(30 \%$ of replacement ratio), $\mathrm{Na}_{2} \mathrm{CO}_{3} \mathrm{H}_{2} \mathrm{O}$ is mainly observed while $\mathrm{Na}_{2} \mathrm{SO}_{4}$ is dominant in AAS binder $(30 \%$ of replacement ratio). This reveals that the efflorescence is mainly comprised of sodium compounds regardless of the binder type. The efflorescence from binder with red mud shows that $\mathrm{CaCO}_{3}$ is partially observable (Perez-Villarejo et al. 2012) but sodium compounds are dominantly observable. The efflorescence from binder OPC with red mud is generic alkaline carbonate efflorescence $\left(\mathrm{Na}_{2} \mathrm{CO}_{3} \mathrm{H}_{2} \mathrm{O}\right)$ produced from the reaction between $\mathrm{Na}^{+}$from the red mud and $\mathrm{CO}_{2}$ gas in the atmosphere. This is similar to the mechanism for geo-polymer efflorescence generation, which is caused by abundant $\mathrm{Na}^{+}$from a sodium activator such as $\mathrm{NaOH}$ and water-glass. The formulations of the efflorescence generation in geo-polymer are expressed as Eqs. (3) and (4), respectively (Kresse 1987).

$$
\begin{aligned}
& \mathrm{CO}_{2}(\mathrm{~g})+2 \mathrm{OH}^{-}(\mathrm{aq}) \rightarrow \mathrm{CO}_{3}^{2-}(\mathrm{aq})+\mathrm{H}_{2} \mathrm{O} \\
& 2 \mathrm{Na}^{+}(\mathrm{aq})+\mathrm{CO}_{3}^{2-}(\mathrm{aq})+7 \mathrm{H}_{2} \mathrm{O} \rightarrow \mathrm{Na}_{2} \mathrm{CO}_{3} \cdot 7 \mathrm{H}_{2} \mathrm{O}
\end{aligned}
$$

The efflorescence from binder without OPC is mainly made up with $\mathrm{Na}_{2} \mathrm{SO}_{4}$ from the reaction between $\mathrm{Na}^{+}$supplied from red mud and $\mathrm{SO}_{3}$ from desulfurization gypsum used as the activator for GGBFS. 


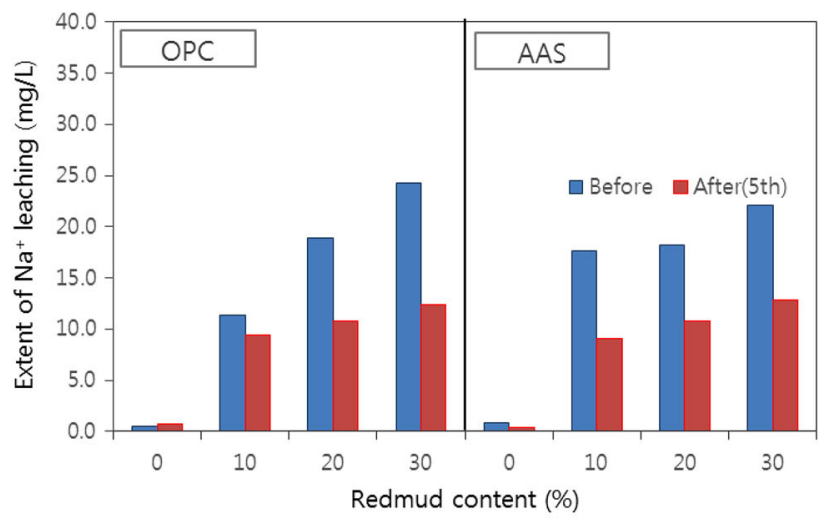

(a) $\mathrm{Na}^{+}$

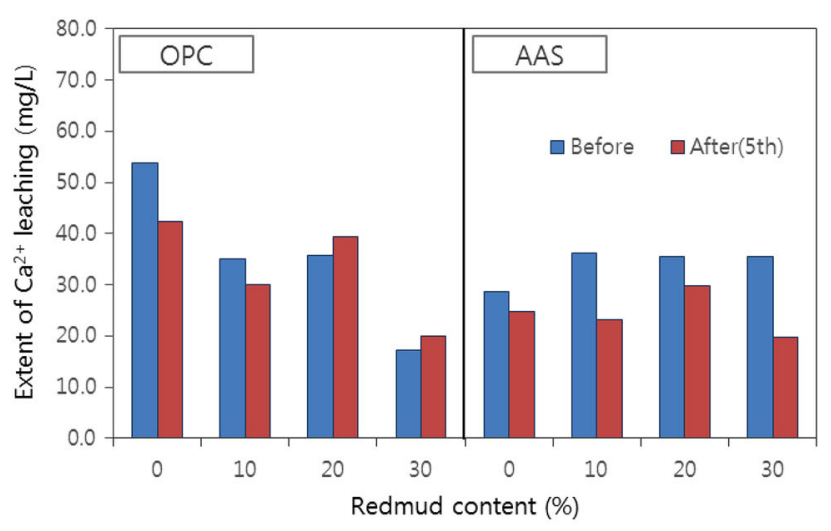

(b) $\mathrm{Ca}^{2+}$

Fig. 11 Results of alkali leaching test with red mud replacement ratio.

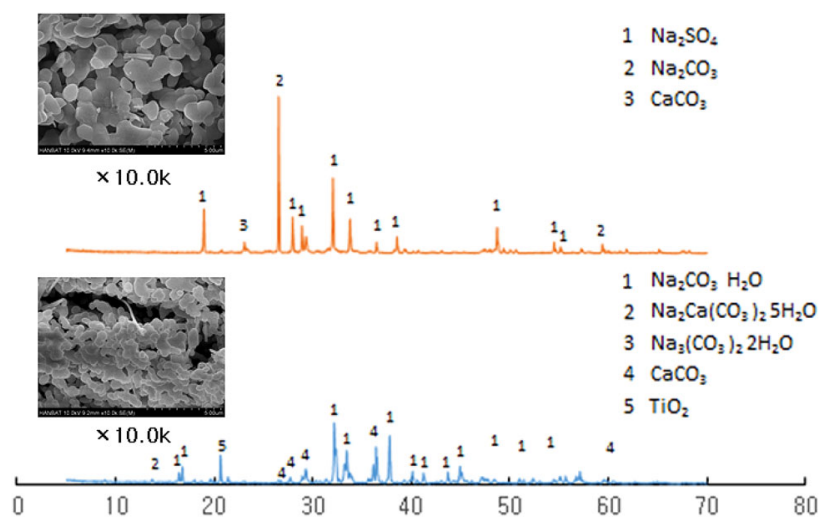

Fig. 12 XRD analysis results of the efflorescence compound

\section{Conclusions}

The conclusions on effects of red mud and alkali-activated slag cement on efflorescence in pavement are as follows.

(1) The OMP (Optimum Moisture Content) increases with higher replacement ratio of red-mud. The OMC is relatively high in AAS pavement compared with that in OPC. The OMC with binder type is shown to be 9.1-10.2\% in AAS and 8.4-9.9\% in OPC, respectively.

(2) The compressive strength at 28 days is evaluated to be 18.9-27.0 $\mathrm{MPa}$ in AAS, and 18.4-28.8 $\mathrm{MPa}$ in OPC, showing a similar level between the cases. The compressive strength is evaluated to be higher than 15.0 $\mathrm{MPa}$ in all specimens regardless of the replacement ratio of red-mud and binder type, which enabled application of red mud for making it appropriate for walking and bike lanes. The optimum replacement ratio for parking lots is evaluated to be within the range of $10 \%$.

(3) Total porosity in ASS is measured to higher than that in OPC. In addition, regarding in terms of the replacement ratio of red-mud, the total porosity volume is evaluated to be higher in OPC but significant difference is not found in AAS. If red-mud is replaced with binder, the cement amount for hydration reaction decreases in OPC, which leads to a reduction in porosity and coarse structure. Meanwhile, AAS is affected less by red mud content, and there is no significance difference in porosity because of a filling effect of red-mud on matrix.

(4) The efflorescence area increases with increasing replacement ratio of red mud and still appeared after 1st cleaning of surface, however it gradually decreases with the repetition of the test.

\section{Acknowledgements}

This research was supported by a Grant (16CTAP-C11520601\#) from Infrastructure and transportation technology promotion research Program funded by Ministry of Land, Infrastructure and Transport of Korean Government. This work also was supported by the National Research Foundation of Korea (NRF) grant funded by the Korea government (MSIP) (No. 2017R1A2B2007967).

\section{Open Access}

This article is distributed under the terms of the Creative Commons Attribution 4.0 International License (http:// creativecommons.org/licenses/by/4.0/), which permits unre stricted use, distribution, and reproduction in any medium, provided you give appropriate credit to the original author(s) and the source, provide a link to the Creative Commons license, and indicate if changes were made.

\section{References}

Adebisi, N. O., Adeyemi, G. O., Oluwafemi, O. S., \& Songeca, S. P. (2013). Important properties of clay content of lateritic soils for engineering project. Journal of Geography and Geology, 5(2), 99-115.

Al-Akhras, N. M., \& Smadi, M. N. (2004). Properties of tire rubber ash mortar. Cement \& Concrete Composites, 26, 821-826. 
Bahmani, S. H., Huat, B. K., Asadi, A., \& Farzadnia, N. (2014). Stabilization of residual soil using $\mathrm{SiO} 2$ nanoparticles and cement. Construction and Building Materials, 64, 350-359.

Bensted, J. (2000). Efflorescence-prevention is better than cure. Concrete, 34, 40-41.

David, D. A., Rania, A. N., Benjamin, A. T., David, O. O., \& Abu, Y. A. (2017). Bauxite red mud-cement based composites: Characterisation for pavement applications. Case Studies in Construction Materials, 7, 45-55.

Dipti, R. B., Umesh, C. S., \& Suresh, R. D. (2015). Characterization of granular lateritic soils as pavement material. Transportation Geotechnics, 6, 108-122.

Dow, C., \& Glasser, F. P. (2003). Calcium carbonate efflorescence on Portland cement and building materials. Cement and Concrete Research, 33(1), 147-154.

Gonga, C., \& Yang, N. (2000). Effect of phosphate on the hydration of alkali-activated red mud slag cementitious material. Cement and Concrete Research, 30, 1013-1016.

Kang, S. P. (2012). A study on the usability of red mud as activator of alkali-activated cementless binder. Journal of the Architectural Institute of Korea Structure \& Construction, 28, 133-140.

Kang, S. P. (2016). Properties of alkali-activated slag-red mud soil pavement using recycled aggregate. Journal of the Korean Recycled Construction Resources Institute, 4(3), 276-283.

Kang, S. P., \& Kwon, S. J. (2017). Effects of red mud and alkali-activated slag cement on efflorescence in cement mortar. Construction and Building Materials, 133, 459-467.
Kani, E. N., Allahverdi, A., \& Provis, J. L. (2012). Efflorescence control in geopolymer binders based on natural pozzolan. Cement \& Concrete Composites, 34(1), 25-33.

Kresse, P. (1987). Efflorescence-mechanism of occurrence and possibilities of prevention. Betonw Fert Tl.-Tech., 53, 160-168.

Liu, X., Zhang, N., Sun, H., Zhang, J., \& Li, L. (2011). Structural investigation relating to the cementitious activity of bauxite residue-Red mud. Cement and Concrete Research, 41, 847-853.

Moon, K. J., Hyoung, W. K., Ju, H. S., Park, W. C., So, S. Y., \& Soh, Y. S. (2009). Pore structure of non-sintering cement using inorganic industrial waste. Journal of Korea Society Waste Management, 26, 128-134.

Pan, Z., Cheng, L., Lu, Y., \& Yang, N. (2002). Hydration products of alkali-activated slag-red mud cementitious material. Cement and Concrete Research, 32, 357-362.

Pan, Z., Li, D., Yu, J., \& Yang, N. (2003). Properties and microstructure of the hardened alkali-activated red mudslag cementitious material. Cement and Concrete Research, 33, 1437-1441.

Perez-Villarejo, L., Corpas-Iglesias, F. A., Martinez-Martinez, S., Artiaga, R., \& Pascual-Cosp, J. (2012). Manufacturing new ceramic materials from clay and red mud derived from the aluminium industry. Construction and Building Materials, 35, 656-665.

Zhang, Z., Provis, J. L., Reid, A., \& Wang, H. (2014). Fly ashbased geopolymers: the relationship between composition, pore structure and efflorescence. Cement and Concrete Research, 64, 30-41. 